\title{
Pathway-Based Toxicity: History, Current Approaches and Liver Fibrosis and Steatosis as Prototypes
}

Catherine Willett ${ }^{1}$, Jessica Caverly Rae ${ }^{2}$, Katy O. Goyak ${ }^{3}$, Brigitte Landesmann ${ }^{4}$ Gary Minsavage ${ }^{3}$ and Carl Westmoreland ${ }^{5}$

${ }^{1}$ The Humane Society of the United States, Washington, DC, USA; ${ }^{2}$ DuPont Haskell Global Centers for Health and Environmental Sciences, Newark, DE, USA; ${ }^{3}$ ExxonMobil Biomedical Sciences, Inc., Annandale, NJ, USA; ${ }^{4}$ Joint Research Centre, Institute for Health and Consumer Protection, European Commission, Ispra, Italy; ${ }^{5}$ Safety \& Environmental Assurance Centre, Unilever Research and Development, Sharnbrook, Bedford, UK

\begin{abstract}
Summary
The Human Toxicology Project Consortium (HTPC) was created to accelerate implementation of the science and policies required to achieve a pathway-based foundation for toxicology as articulated in the 2007 National Research Council report, Toxicity Testing in the $21^{\text {st }}$ Century: $a$ Vision and a Strategy. The HTPC held a workshop, "Building Shared Experience to Advance Practical Application of Pathway-Based Toxicology: Liver Toxicity Mode-of-Action, ” in January, 2013, in Baltimore, MD, to further the science of pathway-based approaches to liver toxicity. This review was initiated as a thought-starter for this workshop and has since been updated to include insights from the workshop and other activities occurring in 2013. The report of the workshop has been published in the same issue of this journal (Willett et al., 2014).
\end{abstract}

\section{History of pathway-based approaches to toxicology}

\subsection{Introduction}

Experience over several decades of characterizing chemical toxicity has led to the realization that a new approach is warranted. Such factors as the large number of relatively uncharacterized chemicals that are already in the environment, the need to generate information for extensive regulatory programs such as the European Union's Registration, Evaluation, Authorization and Restriction of Chemical substances (REACH) program, the high cost and slow pace of animal experimentation and the need to improve the certainty of safety decisions have made it necessary to rethink the traditional approach to hazard and risk assessment, which has generally relied on an extensive array of empirical animal test data (Bradbury et al., 2004). These findings, combined with advances in biological understanding and in experimental technologies (e.g., omics tools, stem cell culturing, reconstructed tissues), have allowed the contemplation of dramatically different approaches to toxicology than those traditionally practiced. One such approach couples existing knowledge of normal biology with new chemical and biological information about the consequences of disturbing that biology, leading to a structured, transparent, and hypothesis-based approach to toxicology. From this thinking the mode of action (MoA), toxicity pathway, and adverse outcome pathway (AOP) approaches have evolved (Ankley et al., 2010; Boobis et al., 2008; NRC, 2007; US EPA, 2006).

\subsubsection{Pathway-based toxicology}

The idea of incorporating mechanistic biochemical information into toxicological assessment is not new; it began with dose-response modeling efforts (for example, see Clewell et al., 1995) and mode-of-action frameworks, such as those developed by the International Program on Chemical Safety (IPCS) to determine human relevance of modes-of-action of pesticides and industrial chemicals leading to carcinogenic (Boobis et al., 2006) and non-carcinogenic (Boobis et al., 2008) toxicity, and the creation of mode-of-action pathways commonly used in drug development (e.g., Iorio et al., 2010) and applied to human disease (e.g., Schadt and Lum, 2006). These efforts were novel in applying mechanistic information about the chemical-biomolecular inter-

Received January 28, 2014; accepted in revised form June 6, 2014; Epub June 23, 2014; http://dx.doi.org/10.14573/altex.1401283

Abbreviations: ALT, alanine; AST, aspartate; AOP, adverse outcome pathway; DILI, drug-induced liver injury; ECM, extracellular matrix; ER, estrogen receptor; HSC, hepatic stellate cell; IPCS, International Program on Chemical Safety; JRC, Joint Research Centre; LXR, liver $X$ receptor; MIE, molecular initiating event; MoA, mode of action; NRC, National Research Council ; OECD, Organization for Economic Cooperation and Development; PPARa, peroxisome proliferator (PP)-activated receptor alpha; PoT, pathway of toxicity; QSAR, quantitative structure activity relationship; ROS, reactive oxygen species; US EPA, US Environmental Protection Agency 
actions to the interpretation of complex empirical data. The notion of toxicity pathways as articulated by the National Research Council in 2007 takes this concept a bit further by envisioning a system-wide network of pathways that leads to a predictive, hypothesis-driven assessment paradigm for toxicity in general (NRC, 2007). In this iteration, the "toxicity pathway" consists of a series of well-described chemical and biological mechanistic steps at progressively higher levels of biological complexity, beginning with the initial perturbation (e.g., chemical exposure) and following through to the eventual biological result (the adverse outcome). This concept also critically includes the notion that adversity is only achieved when homeostasis has been overcome. Recently, this concept has been further formalized for toxicological assessment for both human health and ecological endpoints as the adverse outcome pathway (AOP) (Ankley et al., 2010). The Organization for Economic Cooperation and Development (OECD) has become a driving force in the development and use of AOPs, initially as a mechanism for facilitating the grouping of chemicals within the OECD Toolbox that has developed into a fundamental organizing principle for test guideline development (OECD, 2011). ${ }^{1}$

\subsubsection{Mode-of-action frameworks}

The IPCS cancer and non-cancer MoA frameworks outline a systematic process of describing chemical MoA in animals and comparing those with likely MoA in humans to determine human relevance (Meek et al., 2003). Several founding principles of pathway-based approaches are articulated in the original IPCS frameworks: MoA is defined as a series of key events along a biological pathway from the initial chemical interaction through to the toxicological outcome; a recognition that a MoA does not need to be complete to be useful and that its use depends on the level of completeness (e.g., an incomplete MoA can inform testing strategies but is likely not sufficient to support hazard classification); a focus on a single MoA at a time while recognizing that a chemical may have more than one MoA and that several modes may be related; definition of a "key event" as a step in the pathway that is critical to development of the toxicological outcome and is measurable; a requirement to systematically establish causation between key events; the importance of establishing quantitative parameters in order to apply the MoA to risk assessment; and the need to establish relevance to human biology. In this context, mode-of-action is distinguished from mechanism of action: the latter being defined as a more detailed description of the pathway that includes molecular interactions. There is some disagreement between pathway-based approaches on the definition of these terms, and this definition is one of at least two definitions of mode and mechanism of action (see Table 1 for a summary of pathway-related terms).

Establishing evidence for the MoA hypothesis is based on the Bradford-Hill criteria for establishing causation: strength of association, consistency of the evidence, specificity of the relationship, consistent temporal relationships, dose-response relationships, biological plausibility, coherence of the evidence, and consideration of alternative explanations (Bradford-Hill, 1965).
The IPCS frameworks recommend determining human relevance by answering four key questions: 1) Is there sufficient weightof-evidence for the MoA in animals? 2) Can human relevance be excluded on the basis of qualitative differences in key events? 3) Can human relevance be excluded on the basis of quantitative differences in key events? 4) Do the quantitative differences affect the default uncertainty factors applied in risk assessment?

The MoA framework has been updated to accommodate insights from the expanding application of pathway-based approaches to risk assessment in general (Meek et al., 2014). Similar to the AOP concept, the updated MoA framework more explicitly describes the contribution of information at different levels of biological complexity, for example by describing early key events as being more related to chemical characteristics (of the molecular initiating event (MIE)) and later key events as being less chemical-specific and more of a common expected consequence of earlier key events. In this framework, MoA and AOP are conceptually similar, with a distinction in that MoA does not necessarily imply adversity; it can also refer, for example, to efficacy of a drug (Tab. 1). The updated MoA framework also extends through to the adverse outcome (or therapeutic effect) - this was considered a distinction of AOPs in the 2010 Ankley paper. Two applications of the updated framework are presented: for observed (in vivo) effects and for hypothesized events, and case studies are presented for each, providing concrete examples of the integration of information, using modified Bradford-Hill criteria, to transparently document the level of confidence of information to support regulatory decisions.

MoA frameworks have been incorporated into toxicological assessment guidance by the US Environmental Protection Agency (US EPA) and others (US EPA, 2007; Carmichael et al., 2011). Some limitations to the use of this approach have been that traditional animal tests do not provide data to support MoA development or assessment, therefore, such assessment requires a fair amount of additional specialized animal experimentation as well as in vitro analyses. In addition, it is difficult to ascertain when enough information has been obtained for sufficient weight-of-evidence. Other barriers include a lack of harmonized terminology and assessment methods as well as human information for comparison (note, these issues pertain to all pathwaybased approaches at the moment) (Carmichael et al., 2011).

\subsubsection{Toxicity pathways and the NRC "vision"}

In its, by now, seminal 2007 report Toxicity Testing in the $21^{\text {st }}$ Century: A Vision and a Strategy, the National Research Council panel describes a "transformative paradigm shift" that "envisions a new toxicity-testing system that evaluates biologically significant perturbations in key toxicity pathways by using new methods in computational biology and a comprehensive array of in vitro tests based on human biology" (NRC, 2007). In this context, a "toxicity pathway" is a normal biological pathway that becomes perturbed beyond the point of homeostatic correction leading to toxicity. A description of toxicity begins with chemical characterization, progresses through elucidation of the chemical interaction with the biological system (the pathway),

\footnotetext{
${ }^{1} \mathrm{http}: / /$ www.oecd.org/chemicalsafety/testing/adverse-outcome-pathways-molecular-screening-and-toxicogenomics.htm
} 
Tab. 1: Use of pathway-related terms

\begin{tabular}{|c|c|c|}
\hline \multirow[t]{4}{*}{$\begin{array}{l}\text { Adverse Outcome } \\
\text { Pathway }\end{array}$} & Ankley et al., 2010 & $\begin{array}{l}\text { "A conceptual construct that portrays existing knowledge concerning } \\
\text { the linkage between a direct molecular initiating event (e.g., a molecular } \\
\text { interaction between a xenobiotic and a specific biomolecule) and an adverse } \\
\text { outcome at a biological level of organization relevant to risk assessment." } \\
\text { The AOP is seen as encompassing both the MoA and toxicity pathway. }\end{array}$ \\
\hline & OECD, 2012 & $\begin{array}{l}\text { "An adverse outcome pathway (AOP) is the sequence of events from the } \\
\text { chemical structure of a target chemical or group of similar chemicals through } \\
\text { the molecular initiating event to an in vivo outcome of interest. Each AOP } \\
\text { represents the existing knowledge concerning the linkage(s) between a } \\
\text { molecular initiating event, intermediate events and an adverse outcome at } \\
\text { the individual or population level." }\end{array}$ \\
\hline & OECD, 2013 & $\begin{array}{l}\text { "An AOP is a sequence of events from the exposure of an individual or } \\
\text { population to a chemical substance through a final adverse (toxic) effect at } \\
\text { the individual level (for human health) or population level (for ecotoxicological } \\
\text { endpoints). The key events in an AOP should be definable and make sense } \\
\text { from a physiological and biochemical perspective. AOPs incorporate the toxicity } \\
\text { pathway and mode of action for an adverse effect. AOPs may be related to } \\
\text { other mechanisms and pathways as well as to detoxification routes." }\end{array}$ \\
\hline & Meek et al., 2014 & $\begin{array}{l}\text { The new MoA framework describes MoA as conceptually similar to an AOP } \\
\text { except that MoA is not necessarily adverse (see below under MoA). }\end{array}$ \\
\hline \multirow[t]{2}{*}{ Intermediate Event } & Ankley et al., 2010 & $\begin{array}{l}\text { Refers to "intermediate endpoints" as the endpoints linking adverse outcomes } \\
\text { to molecular initiating events. }\end{array}$ \\
\hline & OECD, 2013 & $\begin{array}{l}\text { Biological events that lie "between the molecular initiating event and the apical } \\
\text { outcome" from which the key events are identified. }\end{array}$ \\
\hline \multirow[t]{3}{*}{ Key Event } & Boobis et al., 2008 & $\begin{array}{l}\text { "Key events are those events that are critical to the induction of the toxicological } \\
\text { response as hypothesized in the postulated MOA and are also measurable." }\end{array}$ \\
\hline & OECD, 2008 & $\begin{array}{l}\text { "A key event is an empirically observed precursor step that is itself a necessary } \\
\text { element of the mode of action or is a biologically based marker for such an } \\
\text { element." }\end{array}$ \\
\hline & Meek et al., 2014 & $\begin{array}{l}\text { "An empirically observable step or its marker, which is a necessary element of } \\
\text { the mode of action critical to the outcome (i.e., necessary, but not necessarily } \\
\text { sufficient in its own right); key events are measurable and reproducible." }\end{array}$ \\
\hline \multirow[t]{2}{*}{ Mechanism of Action } & EPA 2009 & $\begin{array}{l}\text { "Mechanism of action implies a more detailed understanding and description } \\
\text { of events, often at the molecular level, than is meant by mode of action." }\end{array}$ \\
\hline & ECETOC, 2007 & $\begin{array}{l}\text { "A complete and detailed understanding of each and every step in the sequence } \\
\text { of events that leads to a toxic outcome." }\end{array}$ \\
\hline \multirow[t]{3}{*}{ Mode of Action (MoA) } & ECETOC, 2007 & $\begin{array}{l}\text { "A common set of biochemical, physiological, or behavioral responses that } \\
\text { characterize an adverse biological response where major, but not necessarily } \\
\text { all, linkages between a direct initiating event and an adverse outcome are } \\
\text { understood." }\end{array}$ \\
\hline & EPA, 2009 & $\begin{array}{l}\text { "A sequence of key events and processes, starting with interaction of an agent } \\
\text { with a cell, proceeding through operational and anatomical changes, and } \\
\text { resulting in an adverse health effect." }\end{array}$ \\
\hline & Meek et al., 2014 & "A biologically plausible series of key events leading to an effect." \\
\hline \multirow{2}{*}{$\begin{array}{l}\text { Molecular Initiating } \\
\text { Event }\end{array}$} & Ankley et al., 2010 & "A molecular interaction between a xenobiotic and a specific biomolecule." \\
\hline & OECD, 2011 & $\begin{array}{l}\text { The initial point of chemical-biological interaction within the organism that starts } \\
\text { the pathway. }\end{array}$ \\
\hline Pathway of Toxicity & Kleensang et al., 2014 & $\begin{array}{l}\text { Working definition: "A molecular definition of cellular processes shown to } \\
\text { mediate adverse outcomes of toxicants" }\end{array}$ \\
\hline Toxicity Pathway & NRC, 2007 & $\begin{array}{l}\text { "A cellular response pathway that, when sufficiently perturbed, is expected } \\
\text { to result in an adverse health effect." This definition does not explicitly include } \\
\text { the adverse effect itself. }\end{array}$ \\
\hline
\end{tabular}


involves targeted testing to query effects at critical steps of the pathway, and dose-response extrapolation to estimate human exposures required to elicit the effect. Additional populationbased modeling is required to predict ecological effects. The level of assessment required depends on the risk context (e.g., for prioritization or risk assessment).

\subsubsection{The Adverse Outcome Pathway (AOP) approach}

A similar approach, the AOP approach, arose from the field of ecotoxicology (primarily at the International QSAR Foundation ${ }^{2}$ and the Mid-Continent Ecology Division of the EPA in Duluth, $\mathrm{MN}$ ) as a way of addressing uncertainty in risk assessment for an increasing number of chemicals and endpoints - and as required by new legislation. As described by Ankley et al. (2010), an AOP is a flexible framework that can include linking relationships that are "causal, mechanistic, inferential, or correlation based, and the information on which they are based may derive from in vitro, in vivo, or computational systems" and can encompass both mechanism and mode-of-action. An AOP describes the events that occur following chemical exposure, beginning with the molecular interaction of the chemical with a biomolecule (e.g., a protein, receptor, etc.), i.e., the molecular initiating event (MIE), followed by a description of the sequential cellular and tissue perturbations that lead to an eventual toxicological effect - or adverse outcome - which is at the individual level for most human health endpoints or at the population level for environmental endpoints (Fig. 1). The AOP framework allows for the integration of all types of information at different levels of biological organization, from molecular to population level, to provide a rational, biologically based argument (or series of hypotheses) to predict the outcome of an initiating event. In this description, the AOP builds on the MoA concepts and includes the "toxicity pathways" as described in the 2007 NRC report.

The AOP concept is useful in developing a predictive toxicological framework in several ways. In the near-term, even incomplete AOPs can inform chemical grouping or categories and structure activity relationships, they can aid in increasing certainty of interpretation of both existing and new information, and they can be used to inform integrated testing strategies that maximize useful information gained from minimal testing (OECD , 2013). In the longer-term, as they become more completely described and quantitative, information is added to the links between steps, AOPs can be used to identify intermediate or key events for which non-animal tests can be developed, thereby facilitating transparent, mechanism-based, predictive toxicological assessments with low uncertainty and high human relevance, and ultimately without the use of animals. As an AOP is developed, it is important to clearly define its completeness, as that will determine its potential use and applicability.

In 2009, the Society of Environmental Toxicology and Chemistry held a Pellston workshop on "Predictive Ecotoxicology in the $21^{\text {st }}$ Century" that explored two main practical aspects of creating a pathway-based framework for regulatory decision making: linkage (linking observations at different levels of biological complexity to individual or population effects) and extrapolation (quantitative tools that can extrapolate cell- or tissue-level data to individuals or populations) (for an overview, see Villeneuve and Garcia-Reyero, 2011). AOPs serve the purpose of linking observations at all levels of biological complexity and can identify alternative endpoints for use in hazard assessment. During the Pellston workshop, two complementary approaches to AOP development were demonstrated by case examples: using domoic acid as a case study, an AOP was created from existing information in the literature (Watanabe et al., 2011); using disruption of the hypothalamus-pituitary-gonadal endocrine axis in fathead minnows as a case study, omics data were used to reverse-engineer pathways (Perkins et al., 2011). Two other publications from that workshop explore quantitative prediction models that begin to address consideration of the complexities of predicting outcomes at higher-level biological organization from information at relatively less complex levels,

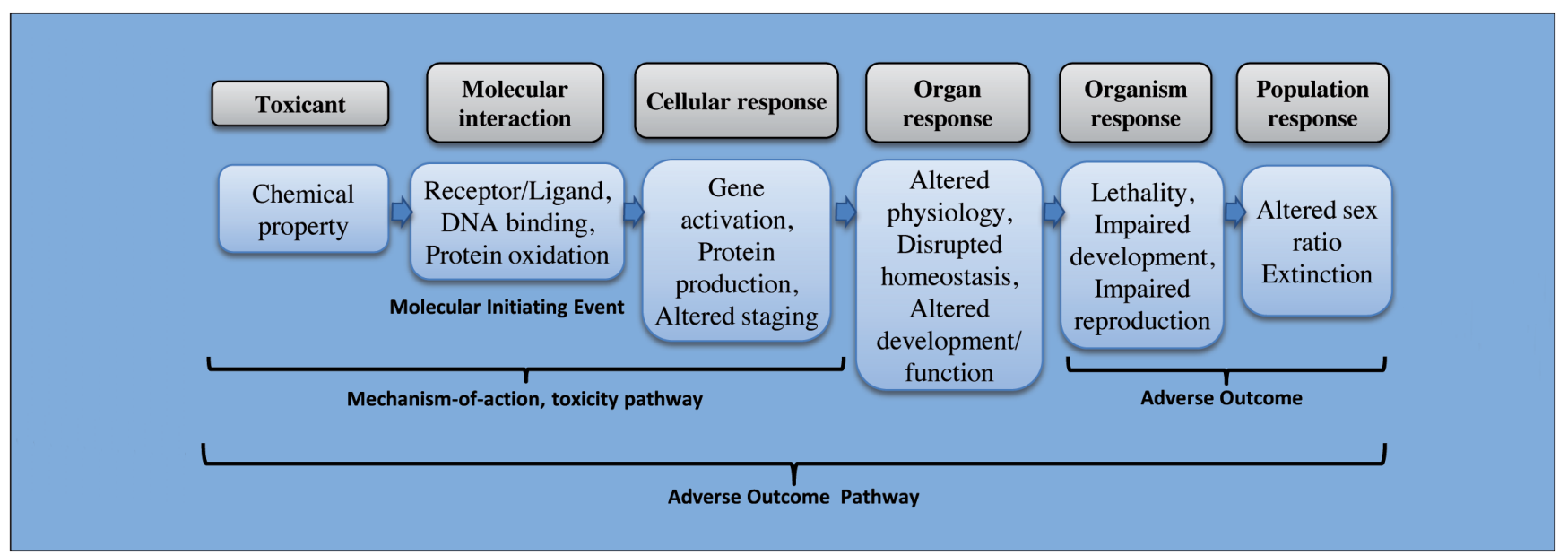

Fig. 1: The adverse outcome pathway (AOP)

The AOP is a biological map from the molecular initiating event through the resulting adverse outcome that encompasses both mechanism and mode-of-action. Adapted from Ankley et al. (2010) and OECD (2013).

2 http://qsari.org/index.php/software/100-effectopia (accessed 19.09.2013) 
including homeostasis (Nichols et al., 2011), species differences (Celander et al., 2011) and extrapolation to population-level effects (Kramer et al., 2011).

\subsubsection{Organization for Economic Cooperation and Development (OECD) AOP Project}

The OECD held a "Workshop on Using Mechanistic Information in Forming Chemical Categories" in 2010, one of the first workshops to gather scientific expertise to guide further AOP development (OECD, 2011). The 2010 workshop focused on the use of AOPs in building chemical categories for read-across, how AOPs might be used in approaches to integrated testing and assessment (IATA) and in identifying key events. For the purposes of the workshop, an AOP was defined as "a narrative which delineates the documented, plausible, and testable processes by which a chemical induces molecular perturbations and the associated biological responses which describe how the molecular perturbations cause effects at the subcellular, cellular, tissue, organ, whole animal and (if required) population levels of observation" (Tab. 1; OECD, 2011). Based on discussion of several case studies, AOPs were further defined as being based on a single, defined MIE that is linked to a specific in vivo hazard outcome. The workshop also discussed development of a template that would summarize all of the information supporting the AOP, including 1) the level of qualitative understanding of the AOP; 2) consistency of the experimental data; 3) confidence in the AOP, and 4) level of quantitative understanding of the AOP (OECD, 2011).

Since the 2010 workshop, OECD has published guidance and a template for development that is currently undergoing further revision (OECD, 2013). The published guidance includes a description of the elements and uses of AOPs, a glossary of terms and a template for developing an AOP. The goals of this guidance are to provide consistency in structure and facilitate harmonized use of AOPs.

According to the OECD guidance, an AOP consists of three main elements: one molecular initiating event (Anchor 1), one adverse outcome (Anchor 2) and any number of intermediate events. While in reality a MIE can be associated with a number of adverse effects and, similarly, an adverse effect can result from a number of different MIE, to streamline the development and use of AOPs, OECD has defined an AOP as being a linear pathway from one MIE to one adverse outcome. A full description of a MIE should include cellular/tissue location as immediately elicited intermediate events may be similar in two different AOPs but differ in cell-type or tissue location (for example, metabolic transformation of a chemical to an electrophilic species may occur in both skin sensitization and liver fibrosis - only in keratinocytes for the former and hepatocytes for the latter). In order for an intermediate event to be identified as a "key event," it must be able to be evaluated experimentally and causally linked to the adverse outcome. A key event may be shared between two or more AOPs. The guidance describes the process for evaluating weight-of-evidence for each step in the development of an AOP.

Similar to the IPCS MoA frameworks described above, the OECD guidance suggests evaluation following the Bradford-Hill principles. In addition, the guidance recommends evaluating the confidence in each element of the AOP, specifically to address the following: How well characterized are the MIE, adverse outcome and each intermediate or key event? What are the limitations of the evidence used to support the AOP? What are the specific parameters of the AOP (e.g., life stage, tissue, etc.)? To what degree are the AOP elements conserved across species?

AOPs have a number of potential uses, including 1) supporting chemical category formation and read-across (predicting the toxicity of one chemical based on results from a structurally related chemical), 2) priority setting for further testing, 3) hazard identification 4) classification and labeling, and 5) risk assessment. As use progresses from 1-5, a corresponding increase in the level of evidence and certainty is necessary for adequate confidence. An AOP can also form the basis for an integrated approach to testing and assessment (IATA) or an integrated testing strategy (ITS) that would be designed to increase the certainty of any decision made regarding a particular substance (OECD, 2013).

There are currently more than 20 AOP projects in the OECD work plan, including pathways and case studies (an AOP that is related to one specific chemical). ${ }^{3}$ In addition, OECD is collaborating with the European Commission's Joint Research Centre (JRC) and the US EPA to develop the AOP Knowledge Base (AOP KB; described in more detail in the next section).

\subsubsection{AOP Knowledge Base and related projects}

To develop a system of AOPs that covers the broad spectrum of biological pathways that are likely to be involved in human health and ecological risk assessment, it is necessary to create a unified knowledge base for AOPs and their supporting evidence that integrates information from all scientific sectors, including toxicology, drug development, disease, medicine and research. An Adverse Outcome Pathway Knowledge Base (AOP KB) is currently being developed by the OECD Extended Advisory Group on Molecular Screening and Toxicogenomics (EAG MST) and is being implemented by the JRC and the US EPA. ${ }^{3,4,5,6,7}$ The AOP $\mathrm{KB}$ is an IT system to capture, manage and share AOP information and will consist of three modules: 1) AOP-WIKI, a textbased tool allowing the management of AOP-related knowledge (AOPs, key events, relationships between them) in a Wikipedialike environment, 2) a graphical tool implementing quantitative models depicting the relationship between two events in an AOP (Effectopedia) and 3) an Intermediate Effects Database (AOP

\footnotetext{
3 http://www.oecd.org/env/ehs/testing/listsofprojectsontheaopdevelopmentprogrammeworkplan.htm

${ }^{4}$ http://ihcp.jrc.ec.europa.eu/our_activities/alt-animal-testing-safety-assessment-chemicals/improved_safety_assessment_chemicals/firstrelease-of-aop-wiki

5 http://www.epa.gov/research/priorities/docs/aop-wiki.pdf

6 http://aopkb.org/aopwiki/index.php/Main_Page

7 http://www.epa.gov/ncct/download_files/chemical_prioritization/AOPWikiTutorial\%20v2.pdf
} 
Network tool) to manage information about intermediate effects triggered by chemicals.

The first available module, the AOP Wiki, leads AOP developers through the steps necessary to capture the scientific information needed to document an AOP - following and implementing OECD guidance on how to describe AOPs. The Wiki also provides a collaborative space for groups to develop AOPs independent of geography or organizational boundaries. Currently, a beta version of the AOP Wiki is available only for OECD AOP development teams but the goal is to eventually make this publicly accessible with registration.

\subsection{Two example AOPs in development and use}

There are several examples of AOPs that are currently used to support decision-making in a number of research and regulatory contexts; the two examples provided below were among the first examples to be developed and were presented at the "Workshop on Using Mechanistic Information in Forming Chemical Categories" (OECD, 2011). At this workshop, the skin sensitization AOP was presented as an example of using mechanistic information in forming categories, i.e., how this information was used in the OECD Toolbox at that time. The AOP is currently also being used to support interpretation and design of integrated testing strategies that are being developed to replace animal testing, primarily in the cosmetics sector (but could have broader applicability; see EC, 2013b). The estrogen receptor-mediated reproductive toxicity AOP was developed to support a quantitative structure activity relationship (QSAR)-assisted decision tree for prioritizing largely inactive chemicals for ecological risk assessment and was presented as a case study at the workshop demonstrating the use of structural requirements for ER-binding, supported by other evidence from key events along the pathway, as a basis for read-across. The development of each of these pathways preceded the OECD guidance; however, both have been incorporated into the OECD Toolbox.

\subsubsection{Skin sensitization}

Skin sensitization is a relatively simple biological process yet involves several cell types and tissues and is a good demonstration of AOP development and use in constructing an integrated testing strategy (Fig. 2). Sensitization occurs in two phases: the first, the induction phase, is a result of initial contact with an allergen and primes the system; the second, the elicitation phase, is in response to a subsequent exposure and results in an allergic response. As with the local lymph node assay (LLNA), the sensitization AOP focuses on the induction phase.

Sensitization can occur via a few different MIEs, such as reactivity with certain metals or reduction-oxidization cycling. This AOP describes sensitization occurring via the covalent modification of proteins on the cell surface of skin cells, specifically reactions of organic chemicals with thiols (e.g., on cysteine) and primary amines (e.g., lysine). Therefore the MIE is covalent reaction with proteins (OECD, 2012).

The induction phase involves initial contact and penetration of the outer dermis of the skin by a potential sensitizer. Metabo- lism in the skin can either activate or deactivate the chemical (or have no effect); chemicals that are electrophilic after penetrating the skin are more potent sensitizers than non-electrophiles. The electrophile then interacts irreversibly with nucleophilic sites in proteins (e.g., cysteine and lysine residues) to form a hapten-protein complex in the epidermis - this is the sensitization MIE. In both dendritic cells (antigen-processing cells in the skin) and keratinocytes (the predominant epidermal skin cells), the presence of a hapten-protein complex elicits the production of cytokines that in turn stimulate dendritic cells to migrate to regional lymph nodes and activate $\mathrm{T}$ cells there. In the lymph node, hapten-protein fragments are presented in complex with MHC molecules by dendritic cells to immature T cells, causing the maturation of memory T cells and the acquisition of sensitivity - this is the key physiologic response of the initiation phase.

The summary of the scientific evidence supporting the AOP indicates that the MIE is very well supported and the key events are qualitatively well supported and therefore the AOP is appropriate for qualitative hazard identification; however, the measurements sufficient for determining potency have not yet been defined (OECD, 2012). The AOP is thought to be applicable generally for mammals without age or sex restriction.

The sensitization AOP is being used to design and interpret integrated assessment strategies that include non-test (e.g., QSAR), in vitro and in vivo test results. Such assessment strategies are being developed by a number of research groups (OECD, 2012; Aeby et al., 2010; Bauch et al., 2011; EU $7^{\text {th }}$ Framework Programme Sens-it-iv ${ }^{8}$; Jaworska et al., 2011; Lambrechts et al., 2010; Natsch et al., 2013; McKim et al., 2012). For example, Bauch et al. (2011) investigated the use of four assays, the direct peptide reactivity assay (DPRA), the KeratinoSense ${ }^{\mathrm{TM}}$ assay (a cell-based reporter gene assay for Nrf2 activity), and the dendritic cell activation assays using the cell lines U-937 cells (MUSST) and THP-1 cells (h-CLAT). The results of each assay were compared with both human and LLNA data, with overall accuracy for 23 substances between $83 \%$ and $91 \%$ compared to human patch test data and between $78 \%$ and $91 \%$ compared to LLNA data. The authors noted that a combination of the MUSST and KeratinoSens ${ }^{\mathrm{TM}}$ assays resulted in $100 \%$ accuracy for the 23 compounds and suggested verifying these results using a larger chemical set. As of this writing, the JRC's European Union Reference Laboratory for Alternatives to Animal Testing (EURL-ECVAM) has recommended use of two assays, DRPA and KeratinoSens ${ }^{\mathrm{TM}}$ to support identification of sensitizers and non-sensitizers as parts of integrated strategies to assess potency according to GHS; it was noted, however, that such strategies remain to be identified (EC, 2013a, 2014). Research is ongoing to identify assays and integrated strategies that will allow potency assessment.

\subsubsection{Estrogen receptor-mediated reproductive toxicity}

This AOP was established to address EPA's regulatory need to assess tens of thousands of chemicals and identify priority chemicals for further assessment and serves as the mechanistic

8 http://www.sens-it-iv.eu 


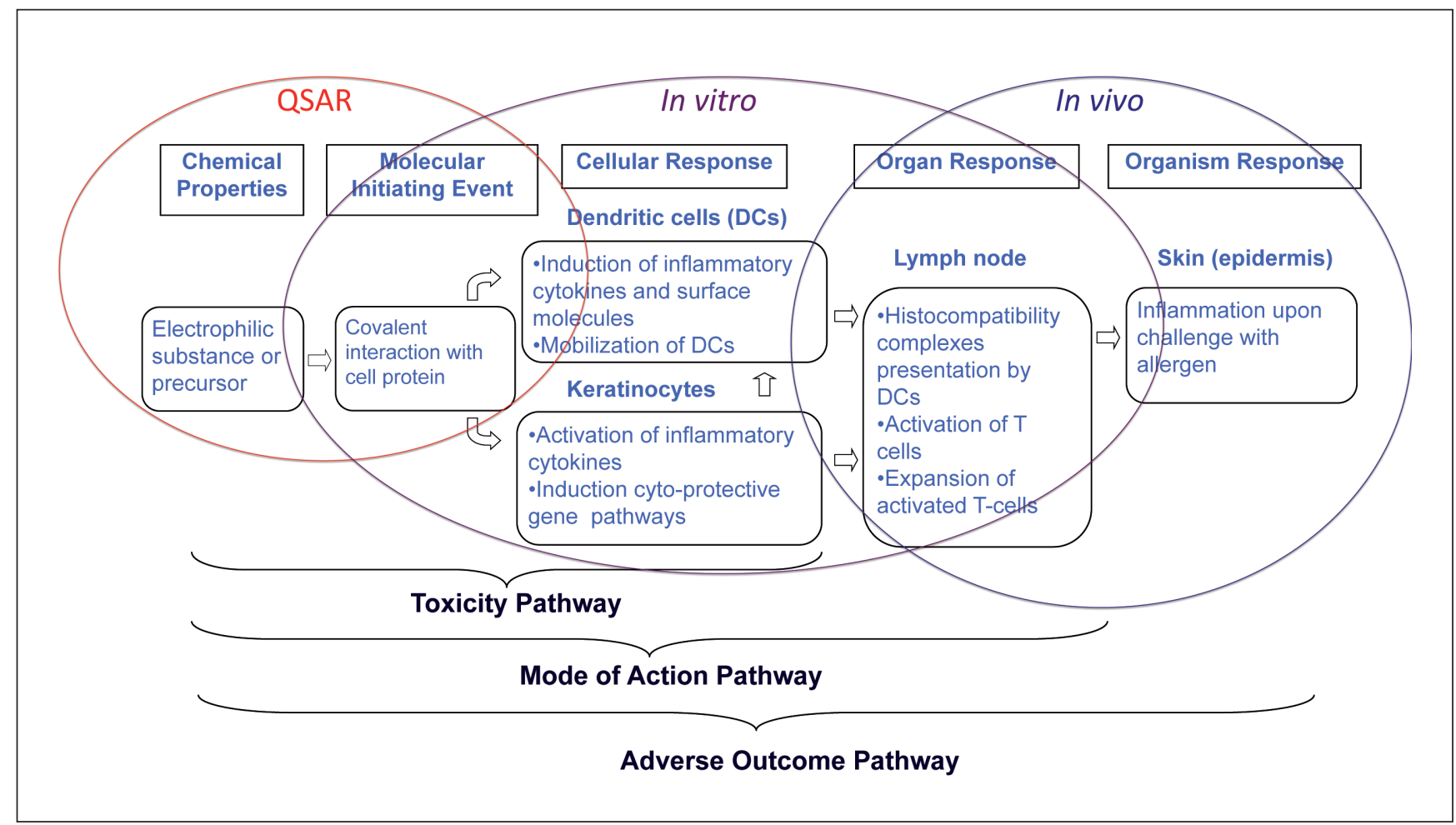

Fig. 2: Flow diagram of the pathways associated with skin sensitization

Delineated below the diagram are the pathway subtypes: Toxicity pathway as defined by the 2007 NRC report, Mode-of-Action pathway as discussed in the WHO/IPCS guidance and adverse outcome pathway as defined by Ankley, et al. (2010). Adapted from OECD (2012).

basis for a QSAR-based expert system for chemical prioritization (OECD, 2011; US EPA, 2012). The expert system was originally developed to cover two specific inventories of interest that are expected to be weak binders: food use pesticide inert ingredients (FI), and antimicrobial active ingredients (AM).

Since a large percentage of estrogen-active compounds function through the estrogen receptor (ER) in a wide range of species, the MIE for this pathway is ER binding. Initiation of events by a chemical binding the estrogen receptor (ER) occurs as a result of sufficient chemical uptake into the organism and partitioning to a target tissue with ER-containing cells followed by changes in expression levels of ER responsive genes. Subsequent changes in ER-responsive protein levels result in changes at the tissue level (e.g., reproductive organs) and eventually can affect reproductive behavior and capacity (Fig. 3) (OECD, 2011; Schmieder et al., 2004; US EPA, 2012). In this AOP description (based on measurements in rainbow trout with elements that are generalizable to all vertebrates), the MIE is chemical binding to the estrogen receptor, the first key event is change in gene expression and protein production (measured via ER-responsive reporters in vitro or endogenous genes ex vivo), a subsequent key event is histopathological changes (e.g., reduced testicular growth, appearance of ova in testes of fish) followed by observation of altered reproductive behavior and sex reversal at the individual level, and finally skewed sex ratios and decreased numbers at the population level.
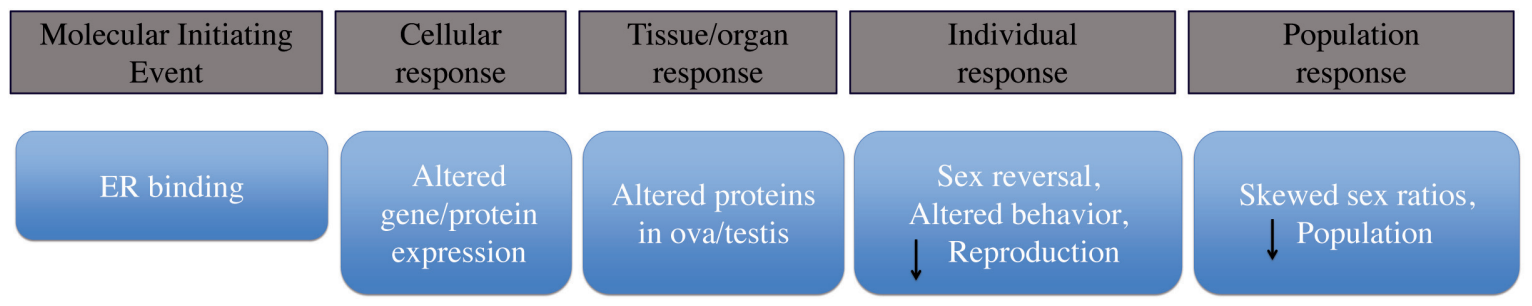

Fig. 3: Outline of AOP for estrogen receptor-mediated reproductive toxicity Adapted from OECD (2011). 
This AOP also provides a biological hypothesis framework for an integrated testing strategy that involves QSAR prediction and measurement of ER binding, measurement of ER transcriptional activity in cells and excised (liver) tissue, histology of sexual organs, and measurement of sexual behavior and fecundity (OECD, 2009).

\subsection{Examples of different approaches to pathway development}

The ongoing projects described below cover examples of different but complementary approaches to developing pathways and assays to support regulatory decisions.

\subsubsection{Pathways of toxicity (PoT) and the human toxome}

The Johns Hopkins School of Public Health Center for Alternatives to Animal Testing (CAAT), along with partners from government and industry, was awarded a \$6 million grant from the National Institutes of Health in 2011 in order to address one of these areas, namely mapping cellular pathways of toxicity (PoT) (Parsons, 2011). The complete complement of these pathways would comprise the "human toxome." The PoT project is focusing on comprehensively mapping the pathways of endocrine disruption in human breast cancer cells as a first step in mapping the human toxome.

A workshop on the "Concept and Tools for Pathways of Toxicity" was held in Baltimore on October 10-12, 2012.9 This workshop introduced the concept of PoT as being similar to the toxicity pathways described in the 2007 NRC report in that they cover the pathway from the MIE up through the first key events at the cellular response level and not necessarily through to the adverse effect. PoT are informed to a greater degree by systems biology approaches than the toxicity pathways envisioned by the NRC report and can identify previously unknown pathways. This approach will complement AOP approaches based on existing and chemical-specific information. The workshop explored ways in which systems biology approaches, including toxicogenomics, proteomics and metabolomics could inform pathway development. Some interesting concepts that were discussed at the 2012 workshop included:

- Systems (omics) approaches and large databases can be used to identify predictive signatures and can be combined together with carefully curated pathways derived from current biological understanding to form complementary approaches to pathway development.

- The bounds of a "pathway" may be fluid over time. At present, the AOP is conceptually bounded by a MIE on one end and a single adverse outcome on the other; however, eventually these pathways will be extended to encompass a more complex network that more accurately reflects biological complexity but is currently thought too unwieldy to be useful for testing strategies.

- There are limitations to basing pathways on current or known biological understanding - bioinformatics can uncover novel branches and not yet described biology - but in practice, we need to start somewhere.

- There is no conceptual difference between pathways based on chemicals and pathways based on drugs - all are a variation from normal biological pathways. There are differences in magnitude, however; drug toxicity is generally a concern at doses that are similar to biologically active doses, whereas (industrial) chemical exposure is generally at low doses relative to biological activity.

Like other pathway approaches, the purpose of PoT is to first do a better job of predicting human health effects of drug and other chemical exposure, to include low dose and consideration of dynamics, and to provide an understanding of the causal linkages underlying "normal" biology. PoT can be used to identify predictive biomarkers of off-target effects, identify key events, front-load toxicity prediction in the drug and green chemistry development process, understand toxicity and also safety, and ultimately to decrease uncertainty in decision-making.

\subsubsection{Hamner Institutes for Health Sciences: pathway-targeted case studies}

In addition to identifying and elucidating critical pathways, assays that measure key steps in these pathways need to be developed and validated, and the information from these assays needs to be tied to biologically relevant changes in humans at known or estimated chemical concentrations. With analytical tools, toxicogenomic data can be used to inform gene groupings or pathways that are modulated by chemical exposure. Analysis of dose-response changes in grouped genes can infer dose-dependent transitions in MoA (Andersen et al., 2013). The Hamner Institutes for Health Sciences is developing a series of pathway-based case studies with the objective being the simultaneous development of assays along with interpretation and extrapolation tools that can be applied to MoA-specific risk and safety estimations, as proof of principle for the approach (Andersen et al., 2012).

\subsubsection{Estrogen receptor signaling}

Taking estrogen signaling as a case study for the pathway approach, the Institute for Chemical Safety Sciences at Hamner Institutes of Health Sciences is initiating a research program whose goal is to identify a series of well characterized in vitro assays that can be used to determine a chemical's risk of disrupting estrogenic signaling (Andersen, 2012). The approach depends on detailed characterization of estrogen signaling, development of refined data interpretation tools, and the creation of prediction and in vitro-in vivo extrapolation models. The project uses human Ishikawa adenocarcinoma cells to characterize ER signaling via ER $\alpha$ and G-protein coupled estrogen receptor (GPER) and compares this with the rat uterotrophic assay (RUA). An array of data is being collected following exposure with strong agonists, including transcriptomics, $\mathrm{Ca}^{2+}$ influx,

\footnotetext{
9 Workshop on the Concept and Tools for Pathways of Toxicity, Baltimore, MD, October 10-12, 2012, sponsored by CAAT and Unilever as part of the NIH Director's Transformative Research Projects Program on "Mapping the Human Toxome by Systems Toxicology" (humantoxome.com/s/Workshop-on-the-Concept-and-Tools-PoT.pdf).
} 
limited phosphoproteomics and ESR1 Chromatin Immunoprecipitation-DNA sequencing (CHIP-seq) data. These data will be analyzed to infer pathway circuitry controlling gene expression and the manner in which the circuitry determines phenotypic responses, generating a computational systems biology pathway (CSBP) model to describe the dose-response of estrogenic effects in these cells. The in vitro data will be compared to detailed pathway analyses of in vivo results from the uterotrophic assay. Finally, the fit-for-purpose in vitro assays will then be used to assess the dose response of several estrogenic compounds for a limited set of endpoints and to generate risk assessments using this data.

The goal of this project is to supplement other pathway-based approaches (e.g., the Tox 21 effort by EPA, NIH and FDA; CAAT's Human Toxome Project) by providing a case study example of the application of the pathway approach directly to human health safety assessment for a specific pathway (in this case, chemicals that act through the ER). Undertaking such a thorough example will provide the basis for and facilitate the same approach being applied to other pathways.

\section{3.2.2 PPARa signaling pathway}

The peroxisome proliferator (PP)-activated receptor alpha $(\operatorname{PPAR} \alpha)$ nuclear receptor is centrally involved in liver cell metabolism. PPAR $\alpha$ is involved in PP-induced carcinogenicity in rodents, and induces fatty acid metabolizing oxidation systems in response to PPs in both rodent and humans (Rao and Reddy, 2004). To map and model the PPAR $\alpha$ signaling pathway, the Hamner project involves the use of arrays of different omics data from primary human and rat hepatocytes treated with a PPAR $\alpha$-specific ligand (Andersen, 2012). Data include microarray-based gene expression data, regulatory interactions inferred from protein-DNA transcription factor arrays and published CHIP-on-chip (chromatin immunoprecipitation followed by microarray hybridization) results combined to form a picture of PPAR $\alpha$-mediated transcriptional regulation following PPAR $\alpha$ activation. This inferred response network will serve as the basis for quantitative computational models of the PPAR $\alpha$ pathway.

\subsubsection{Joint Research Centre: SEURAT-1 workshop on describing mode-of-action in liver toxicity using adverse outcome pathways (Oct 24-25, 2012).}

The 2012 workshop was organized by SEURAT-1 (Safety Evaluation Ultimately Replacing Animal Testing) Mode-of-Action Working Group and $\mathrm{COACH}$, the project coordination activity. The discussion of this workshop and presentation of the two liver-specific pathways in Section 2 below sets the stage for the 2013 workshop report "Building Shared Experience to Advance Practical Application of Pathway-Based Toxicology: Liver Toxicity Mode-of-Action," published in the same issue of this journal (Willett et al., 2014).

SEURAT-1, a FP 7 project co-financed by the European Commission and Cosmetics Europe, is currently the largest European research initiative, composed of six research projects that aim to fundamentally change the way we assess the safety of chemicals. The goal is to move away from safety assessment re- lying on animal experiments towards a paradigm based on using a mechanistic understanding of toxicology to intelligently integrate leading edge computational and in vitro tools into systems that support predictive safety assessment.

The objectives of this expert workshop were to evaluate practical processes and tools for describing and reporting a MoA or AOP, based on elaborated examples, and to consider how such MoA knowledge can be practically applied within SEURAT-1 projects. The workshop also provided an opportunity to bring MoA and AOP practitioners together for sharing the current status of various international activities and to exchange experiences and plans. Various views on MoA/AOP/Tox-Pathway development were captured with the emphasis being more on the building process itself rather than on the actual content of the pathways.

In addition to previously mentioned issues that need to be addressed (e.g., the level of detail determines usefulness, a consistent terminology is needed, animal data may have limited relevance to human pathways, drugs may or may not be a good reference for other chemicals) other topics were highlighted, including the importance of investigating the role of time in individual processes; evidence that clinical data show different outcomes for acute and chronic exposure where it remains unclear whether the same mechanisms are relevant in these scenarios and how adaptation (compensation and repair) could be captured in an AOP.

Several examples of AOPs in development were presented, including those outlining reproductive toxicity, mitochondrial toxicity, carcinogenicity and neurotoxicity. These examples represented diverse approaches - some were based on decisiontrees (e.g., reproductive toxicity), some focused heavily on MIEs (e.g., mitochondrial toxicity), and metabolism was accounted for to greater or lesser degrees. In general, there has been quite a lot of success in using MIEs to identify chemical classes and group chemicals, followed by some initial successes in using next steps (e.g., gene expression or other omics finger-prints) to further identify chemical descriptors and characterize chemical classes. Gene expression and other omics analyses can also provide rich data regarding MoAs and temporal relationships between events in a pathway. Improved computational tools are needed to facilitate interpretation of omics data in terms of biological pathways, including tools that can consider kinetic, dynamic, and homeostatic dimensions.

The enormous complexity and amount of work that has informed each example was apparent. Yet again, the need for a common language was highlighted, as well as the importance of sharing supporting information and pathways as they develop. An important observation was that the experimental design and research needed for pathway elucidation is quite different from the one that applies AOP knowledge. For example, an AOP intended to simply convey mechanistic understanding will differ from one intended to guide hazard identification, which in turn will differ from an AOP that should provide the basis for quantitative risk or safety assessment. In order to satisfy more demanding use-cases, such as the development of integrated assessment and testing strategies for the prediction of in vivo points-of-departure, quantitative rather than purely qualitative 
information in an AOP is indispensable. One unresolved issue was a divergence of opinion about whether it was useful or necessary to describe the sequence of events along the pathway in a linear form.

Two pathways were presented as prototypes for pathway development: MoA from protein alkylation to liver fibrosis, and MoA from liver $\mathrm{X}$ receptor activation to liver steatosis (Landesmann et al., 2012). These prototype pathways are described in more detail in the next section.

\section{Liver toxicity MoAs}

\subsection{Introduction}

Due to its integral function as the central clearing house of the body for exogenous (and endogenous) chemicals, as well as its close proximity to the gut and spleen, the liver is particularly susceptible to toxicity from both parent compounds and metabolites. Liver injury is the most common cause for drug failure in clinical trials and for drugs to be withdrawn from the market.

\subsection{Liver metabolism}

There are two general forms of metabolism that occur in the liver (and in other tissues), Phase I and Phase II. Phase I metabolism primarily increases water solubility of chemicals by oxidation, reduction, hydrolysis, hydration and other less prominent reactions. Oxidation by cytochrome P450 enzymes is the most prevalent Phase I reaction, accounting for approximately $75 \%$ of all drug metabolism (Guengerich, 2008). Cytochrome P450 enzymes comprise the terminal oxidase component of an electron transport chain. Of the 57 members of the cytochrome P450 gene family, the protein products of six are responsible for most drug metabolism: P450s 1A1, 1A2, 2B6, 2C9, 2C19, 2D6 and 3A4. Oxidation by $\mathrm{P} 450$ enzymes requires cofactors to supply and accept electrons (e.g., NAD $(\mathrm{P}) \mathrm{H})$ and coenzymes (e.g., cytochrome $\mathrm{P} 450$ reductase). $\mathrm{P} 450$ s are located in the inner membrane of the mitochondria or on the endoplasmic reticulum, are present in most tissues (although metabolism of most toxic substances, including exogenous chemicals, occurs in the liver) and play a central role in metabolism, including hormone metabolism.

In Phase II metabolism, metabolic intermediates (including those generated by Phase I metabolism) are conjugated to small polar molecules (e.g., glutathione [GSH], sulfate, glycine, glucuronic acid) by transferases (e.g., UDP-glucuronosyltransferases [UGT], N-acetyltransferases [NAT], glutathione S-transferases [GST], sulfotransferases [SULT], acetyl-Co-As), generally to render them inert and target them for excretion. Most Phase II reactions occur in the cytosol.

\subsection{Liver injury/toxicity}

Due to its central role in metabolism of exogenous substances, the liver is susceptible to chemical damage via many direct and indirect mechanisms. Some of these mechanisms include oxidative stress caused by chemicals that interfere with signaling or electron transport in mitochondria and modulation of the cytochrome P-450 system, ultimately leading to cellular necrosis or apoptosis. Hepatocyte damage can also trigger inflammation (hepatitis) and involvement of the immune system, further exacerbating the injury. Acute liver toxicity is generally of one of two types: direct cytotoxicity resulting in necrosis or apoptosis, or indirect cytotoxicity following interference of the flow of bile (cholestasis), either via circulatory obstruction or by disruption of bile metabolism (Tab. 1) (Goodman, 2007; Holt and Ju, 2006). Chronic liver injury can lead to fatty acid accumulation (steatosis), cholestasis, hepatitis (including granuloma formation), accumulation of phospholipids (phospholipidosis) and fibrosis. If the damage is not reversed, injury can ultimately lead to cirrhosis (a build-up of fibrous scar tissue and regenerative tissue nodules causing a loss of liver function) and/or neoplasia.

\subsection{Drug induced liver injury}

Drug-induced liver injury (DILI) is a rare but serious health problem; DILI accounts for $50 \%$ of acute liver failure incidents and is a significant reason for removing drugs from the market. The rare occurrence of DILI ( 1 in 10,000 to 100,000 treated patients; Kaplowitz, 2005) renders it difficult to detect in clinical trials, which highlights the need for a better understanding of underlying mechanisms in order to better predict potential occurrence.

Liver damage caused by drugs has been parsed into two classes: Type A (or intrinsic) damage is the most common (80\% of drug-induced liver injury) and is related to the pharmacological activity of the drug, is dose-dependent and can be explained and predicted by known biological mechanisms; Type B (or idiosyncratic) is neither predictable nor reproducible and can be doseindependent. Idiosyncratic liver injury is rare and thought to be a result of individually variable susceptibility factors and can be classified as allergic or non-allergic (Kaplowitz, 2005). Allergic reactions involve the participation of the adaptive immune system and most likely involve a secondary trigger, such as increased levels of cytokines due to viral or bacterial infection; non-allergenic reactions can have a latency period of several months and be independent of dose. Most frequently it is not the parent drug that is hepatotoxic, but the Phase I metabolite of the drug; more rarely Phase II metabolites are hepatotoxic ( $\mathrm{Au}$ et al., 2011).

Chemicals produce a wide variety of histologically and clinically-described pathologies which have been characterized historically as hepatocellular, cholestatic or mixed (Tab. 2). Hepatocellular injury causes release of aminotransferases (alanine [ALT] and aspartate [AST]) and alkaline phosphatase (ALP); however these enzymes are not liver-specific and occur in several tissues. ALT is thought to be slightly more liver-specific than AST, and an increase of ALT of three-times the upper level of normal (UNL) is considered a sensitive, if not completely specific, marker of hepatocyte injury. In addition, extensive damage interferes with the liver's ability to clear bilirubin from the plasma, causing a rise in plasma bilirubin levels, and is a diagnostic indicator of impaired liver function (known as "Hy's law," after the scientist, Hy Zimmerman, who first made the connection). Hy's Law is informally described as satisfying the following conditions: (a) ALT level more than three times ULN, accompanied by (b) total bilirubin level more than twice 
Tab. 2: Types of toxic liver injury

\begin{tabular}{|c|c|c|}
\hline Injury type & Description & Implicated drugs or chemicals \\
\hline Necrosis & $\begin{array}{l}\text { Direct cell death, often restricted to particular zones of the liver } \\
\text { (zonal necrosis). Associated with high alanine aminotransferase } \\
\text { (ALT). }\end{array}$ & $\begin{array}{l}\text { Paracetamol, carbon tetrachloride, } \\
\text { acetominophen (zonal), methyldopa (non- } \\
\text { zonal) }\end{array}$ \\
\hline Hepatitis & $\begin{array}{l}\text { Cytotoxicity induced inflammation. Three types: 1) histologically } \\
\text { similar to viral hepatitis (most common); 2) focal or non-specific, } \\
\text { where cell death associated with lymphocytic infiltration is in } \\
\text { scattered foci and 3) chronic hepatitis }\end{array}$ & $\begin{array}{l}\text { "Viral" hepatitis: halothane, isoniazid, } \\
\text { phenytoin } \\
\text { Focal: aspirin } \\
\text { Chronic: methyldopa, diclofenac }\end{array}$ \\
\hline Cholestasis & $\begin{array}{l}\text { Impairment of bile flow, results in jaundice, can be associated with } \\
\text { inflammation }\end{array}$ & $\begin{array}{l}\text { Non-inflammatory: Oral contraceptive pills, } \\
\text { anabolic steroids, androgens } \\
\text { Inflammatory: Allopurinol, co-amoxiclav, } \\
\text { carbamazepine } \\
\text { Ductal: Chlorpromazine, flucloxacillin }\end{array}$ \\
\hline Steatosis & $\begin{array}{l}\text { Also known as fatty liver, hepatotoxicity that changes the way liver } \\
\text { cells process fat (triglycerides) resulting in accumulation of fat } \\
\text { deposits, either in small droplet (microvesicular) or large droplet } \\
\text { (macrovesicular) deposits }\end{array}$ & $\begin{array}{l}\text { Microvesicular: aspirin, ketoprofen, } \\
\text { tetracycline (especially if expired) } \\
\text { Macrovesicular: acetaminophen, } \\
\text { methotrexate }\end{array}$ \\
\hline Granuloma & $\begin{array}{l}\text { An inflammatory response resulting in a localized collection of } \\
\text { macrophages. Possibly related to systemic toxicity, idiosyncratic or } \\
\text { asymptomatic }\end{array}$ & $\begin{array}{l}\text { Allopurinol, phenytoin, isoniazid, quinine, } \\
\text { penicillin, quinidine }\end{array}$ \\
\hline Neoplasms & $\begin{array}{l}\text { Both benign and malignant neoplasms have been found in various } \\
\text { hepatic cell types including hepatocytes, biliary epithelial cells } \\
\text { and vascular endothelial cells. Common benign neoplasms are } \\
\text { hepatocellular adenoma and bile duct cysts. Common malignant } \\
\text { neoplasms are hepatocellular carcinoma and angiosarcoma. }\end{array}$ & $\begin{array}{l}\text { Vinyl chloride, combined oral contraceptive } \\
\text { pill, anabolic steroid, arsenic, thorotrast }\end{array}$ \\
\hline Vascular lesions & Damage to the vascular endothelium & $\begin{array}{l}\text { Chemotherapeutic agents, anabolic } \\
\text { steroids, oral contraceptives }\end{array}$ \\
\hline Fibrosis & $\begin{array}{l}\text { Liver fibrosis is a reversible wound healing response to a variety of } \\
\text { chronic injuries including toxic injury from chemicals. Pathogenic } \\
\text { fibrosis typically results from chronic injury with sustained } \\
\text { production of growth factors and fibrogenic cytokines in which } \\
\text { inflammation, tissue destruction and repair processes occur } \\
\text { simultaneously }\end{array}$ & $\begin{array}{l}\text { Ethanol, carbon tetrachloride, } \\
\text { methotrexate, allyl alcohol, }\end{array}$ \\
\hline
\end{tabular}

ULN and in the absence of any other potential cause of liver impairment (e.g., viral hepatitis or preexisting liver disease) (US FDA, 2009). US FDA guidance suggests that a clinical finding of "Hy's Law" in two or more cases indicates a strong potential for DILI, although studies with some drugs suggest this may be too stringent and the search for more predictive markers continues (Kaplowitz, 2005).

\section{Liver toxicity MoAs from the SEURAT-1 project}

The SEURAT-1 project is focusing on an integrated approach to model repeat dose toxicity, and hepatoxicity was chosen as the first case study to define and describe a MoA to a sufficient extent to facilitate conducting a feasibility study (Landesmann et al., 2012). These prototypes were developed following the OECD guidance for AOP development, and the methods used to support pathway development are described. For these prototypes, there is a large amount of data to support the causal linkages between key events, thus in this project, these pathways are described synonymously as AOPs or MoAs. The AOs liver fibrosis and steatosis typically result from chronic injury; the respective MIEs were based on SEURAT-1 reference chemicals for these two adverse effects.

\subsection{Fibrosis: MoA from protein alkylation to liver fibrosis}

Liver fibrosis is the result of a cycle of necrosis/apoptosis and regeneration caused by repeated injury to the liver. An imbalance in the degradation and deposition of extracellular matrix during this cycle results in an accumulation of fibrous extracellular matrix (ECM) that eventually interferes with normal liver function. The SEURAT fibrosis MoA was delineated using information from exposure to allyl alcohol and carbon tetrachloride $\left(\mathrm{CCl}_{4}\right)$.

Briefly (for more detail, see Landesmann et al., 2012): the MIE for both chemicals is protein alkylation: allyl alcohol is oxidized by alcohol dehydrogenase to acrolein which is highly reactive and readily alkylates proteins; $\mathrm{CCl}_{4}$ is oxidized by the cytochrome $\mathrm{P} 450$ system to a reactive $\mathrm{CCl}_{3}$ free radical that 
alkylates proteins and DNA and causes lipid peroxidation, resulting in necrosis.

Alkylation of liver proteins and lipid peroxidation accompanied by oxidative stress triggers apoptotic cell death (Fig. 4). Cell death releases reactive oxygen species (ROS), cytokines and chemokines that trigger oxidative stress, elicit inflammation and activate Kupffer cells (KCs), hepatic stellate cells (HSCs) and platelets. KCs and HSCs are also activated by phagocytosing apoptotic cell remnants.

Activated KCs generate ROS and counterbalancing nitrous oxides, inflammatory mediators including cytokines and chemokines, as well as a number of cytokines that induce HSC proliferation. KCs, platelets and sinusoidal endothelial cells also release TGF- $\beta 1$, which is the most important and potent fibrogenic cytokine. As HSCs become activated they also express TGF- $\beta 1$. TGF- $\beta 1$ in turn further activates HSCs, simulates ECM synthesis and suppresses ECM degradation. This prolonged phase of HSC activation is called the "perpetuation phase", during which HSCs proliferate and release chemokines that enhance inflammation.

Overlapping this process is ongoing oxidative stress associated with an increase in ROS generated by KCs, HSCs and inflammatory cells. Increased ROS further induce fibrillar ECM production. Due to the increase in ROS and chemokines, a state of chronic inflammation is established and facilitates progression of fibrosis. Following the induction of macrophages, other inflammatory cells, such as T, dendritic and natural killer cells, are recruited into the process. As HSCs are activated, they increase fibrosis in two ways; by cellular proliferation and by increasing ECM production per cell. Stimulated HSCs respond to increased ECM and further differentiate into contractile myofibroblasts, which are the primary collagen producing cells.

Additional sources of ECM include bone marrow (which probably gives rise to circulating fibrocytes), portal fibroblasts, EMT (epithelial-mesenchymal cell transition) from hepatocytes and cholangiocytes and MET (mesenchymal-to-epithelial transition), in which mesenchymal cells give rise to epithelium.

Several other signaling pathways influence HSC activation, including adipokines from adipose tissue and infiltrating macro- phages. Liver damage stimulates the local neuroendocrine system which also has the effect of accelerating fibrosis.

Fibrogenesis is a general mechanism that can be induced in many tissue types (e.g., lung, kidney, and lymphoid tissue) any tissue where chronic injury involves a cycle of tissue destruction, inflammation and repair.

\subsection{Steatosis: MoA from liver $X$ receptor activation to liver steatosis}

Steatosis, also known as fatty liver, is the result of an imbalance in triglyceride metabolism and is characterized by the accumulation of lipid within hepatocytes. While steatosis itself is reversible and does not necessarily disrupt liver function (it is not necessarily an adverse outcome), it can be a precursor to liver disease such as non-alcoholic fatty liver disease.

Briefly, one MIE leading to steatosis could be interference with nuclear receptors involved in homeostasis of fatty acid metabolism (Fig. 5). Chemical substances can bind nuclear receptors such as the liver X receptor (LXR), corticosteroid receptors, retinoic acid receptor (RAR), retinoid $X$ receptor (RXR), Vitamin D receptor, peroxisome proliferator activated receptors alpha and gamma (e.g., PPAR $\alpha, \operatorname{PPAR} \gamma)$, pregnane $X$ receptor (PXR), aryl hydrocarbon receptor (AhR), and estrogen receptors (ER) and might perturb normal homeostasis of fatty acid metabolism.

Binding to LXR causes an induction of transcription factors leading to de novo fatty acid and tryglyceride synthesis as well as an influx of fat from peripheral tissues to the liver. There are two isoforms of LXR in mammals (LXR $\alpha$ and $\mathrm{LXR} \beta$ ) that form heterodimers with RXR to bind LXR response elements in the promoters of a number of genes involved in fatty acid metabolism. LXR $\alpha$ is expressed in several tissues but predominantly in liver, while LXR $\beta$ is ubiquitously expressed, and LXR $\alpha$ knockout mice do not develop steatosis, indicating that $\operatorname{LXR} \alpha$ may be more involved in liver-specific activities including steatosis. LXRs can also be regulated by other nuclear receptors, e.g., the $\mathrm{LXR} \alpha$ promoter is regulated by $\operatorname{PPAR} \alpha$ and insulin .

Genes regulated by LXR/RXR include fatty acid synthase, apolipoprotein E, lipoprotein lipase, fatty acid uptake transport-

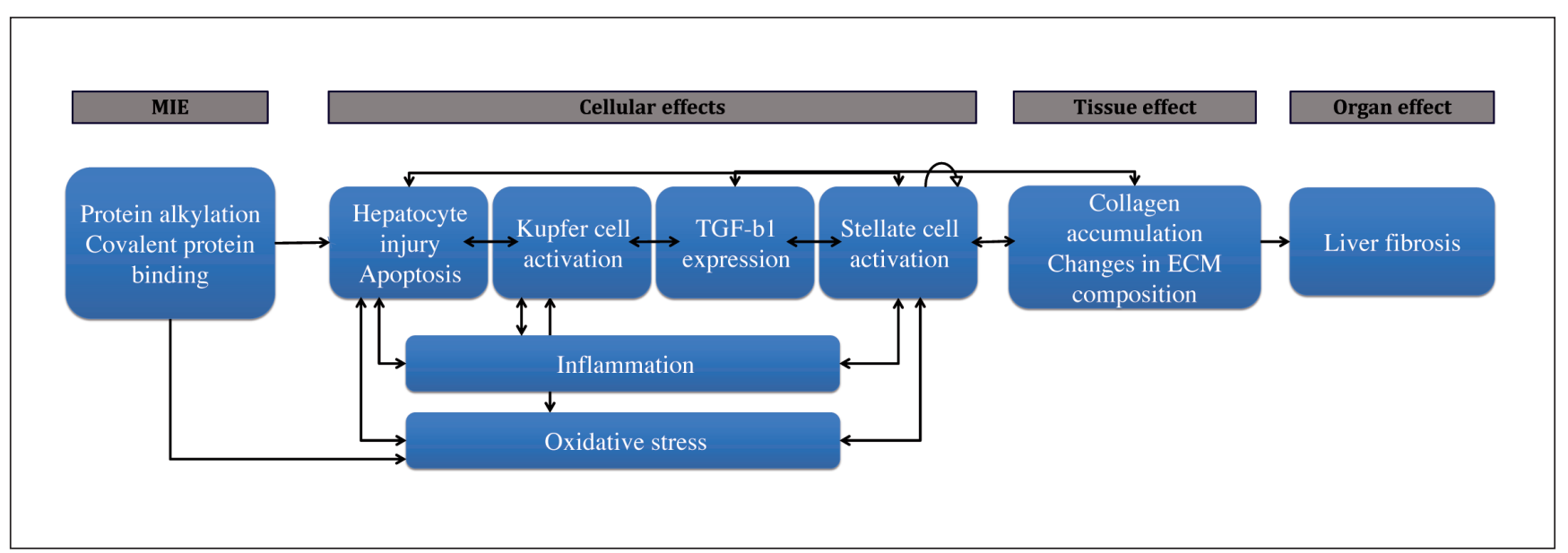

Fig. 4: Flow diagram of the fibrosis MoA

Adapted from Landesmann et al., 2012. 


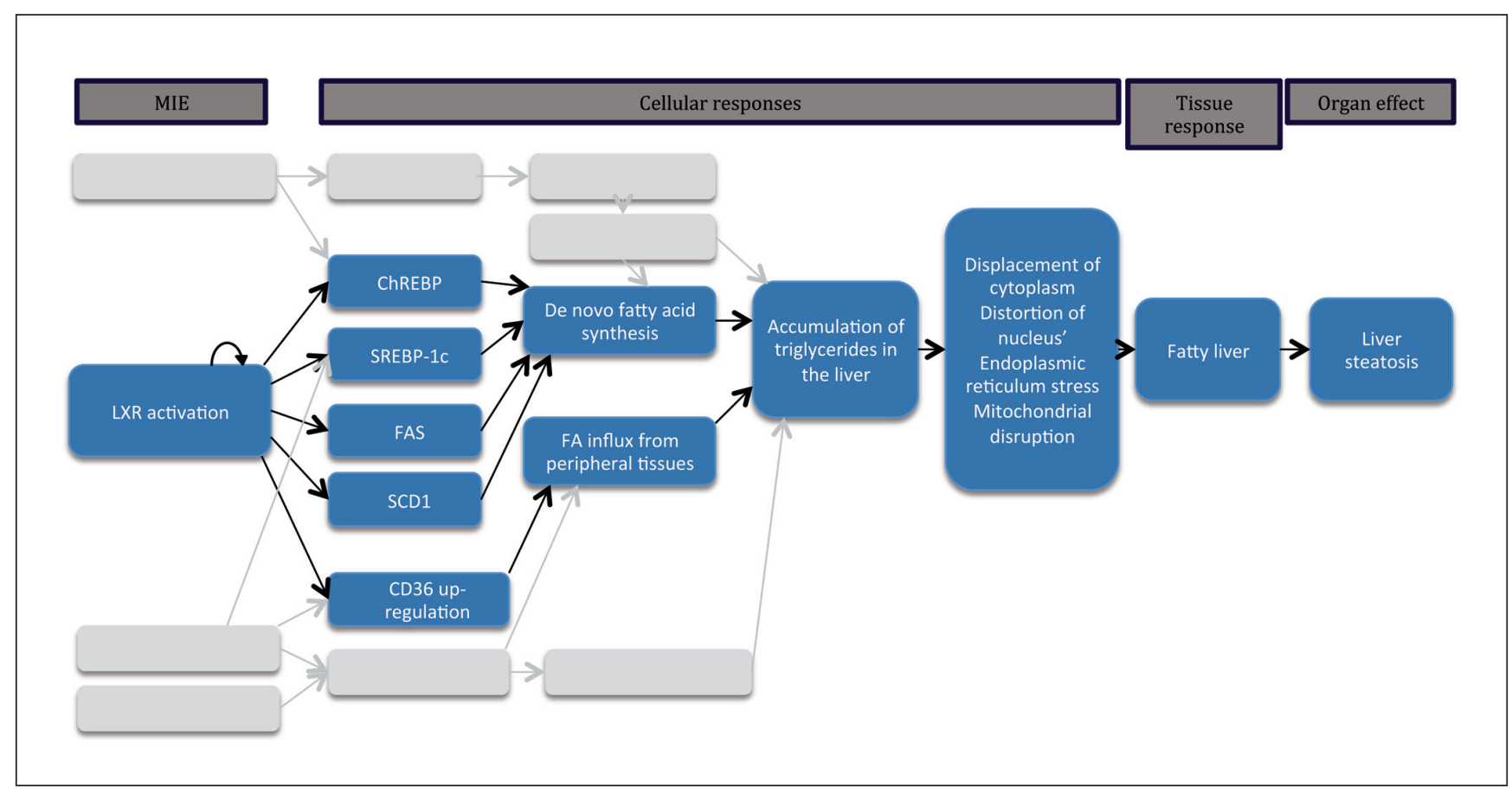

Fig. 5: Flow diagram of MoA from LXR activation to liver steatosis

Adapted from Landesmann et al., 2012.

er, as well as its own promoter and other regulatory proteins such as the carbohydrate response element binding protein (ChREBP) and sterol response element binding protein (SREBP-1c). In turn, ChREBP activates several enzymes involved in glycolysis and lipogenesis, including acetyl-CoA-carboxylase (ACC) and fatty acid synthase (FAS). SREBP-1c induces expression of the genes encoding ACC and FAS. LXR activation also induces expression of stearoyl-CoA-desaturase 1 (SCD1), which is involved in triglyceride accumulation in hepatocytes by an incompletely understood mechanism. In liver cells, the fatty acid translocase (CD36) gene is a target of activated LXR. CD36 mediates uptake and transport of long chain fatty acids in many cell types.

The result of activation of genes and enzymes involved in triglyceride synthesis and fatty-acid uptake in the liver is accumulation of large amounts of fatty acid in hepatocytes. As a result, intracellular hepatic changes include displacement of the nucleus and cytoplasm, possibly accompanied by mitochondrial toxicity and endoplasmic reticulum stress. With continued injury, steatosis can progress to fibrosis and cirrhosis. As indicated, LXR binding is one of several interrelated MIEs that can lead to steatosis.

\section{Summary}

Recent global activities have been focused on initiating a paradigm shift in the way in which drug and chemical toxicity characterizations are conducted; with one major area being the definition and use of pathway-based assessments. To this end, several overlapping and related frameworks have been proposed over time, including modes of action, adverse outcome pathways, toxicity pathways and pathways of toxicity. This review provides an overview of the history of pathway development, use of example AOPs, and several ongoing activities associated with pathway development. Two prototype pathways in liver toxicity are presented in more detail that are being developed as part of the SEURAT project and that were the subject of a 2013 workshop and report published elsewhere in this journal (Willett, et al., 2014). Pathway activities are converging on a set of definitions and principles to demonstrate confidence - principles based on Bradford-Hill criteria as first applied to MoA frameworks (Boobis et al. 2006, 2008; Meek et al., 2014) - that are being formalized in guidance developed by the OECD (2013) and by others ${ }^{10}$ in an effort to globalize and harmonize pathway development.

\section{References}

Aeby, P., Ashikaga, T., Bessou-Touya, S. et al. (2010). Identifying and characterizing chemical skin sensitizers without animal testing: Colipa's research and method development program. Toxicol In Vitro 24, 1465-1473. http://dx.doi.org/10.1016/j. tiv.2010.07.005

Andersen, M. (2012). A Research Plan for a Case Study Approach with Estrogen-Signaling to Accelerate Implementation of the 2007 NAS Report on Toxicity Testing. Research Trian-

\footnotetext{
10 http://ihcp.jrc.ec.europa.eu/our_labs/eurl-ecvam/workshop-on-advancing-adverse-outcome-pathways-for-integrated-toxicology-andregulatory-applications
} 
gle Park: The Hamner Institutes for Health Sciences. http:// www.thehamner.org/content/Tier_1_and_Done.pdf (accessed 19.09.2013).

Andersen, M., Clewell, R. and Bhattacharya, S. (2012). Developing in vitro tools sufficient by themselves for $21^{\text {st }}$ century risk assessment. In T. Gocht and M. Schwarz, Towards Replacement of in vivo Repeated Dose Systemic Toxicity Testing. Vol. 2 (347-360). SEURAT-1 COACH Consortium.

Andersen, M. E., McMullen, P. D. and Bhattacharya, S. (2013). Toxicogenomics for transcription factor-governed molecular pathways: moving on to roles beyond classification and prediction. Arch Toxicol 87, 7-11. http://dx.doi.org/10.1007/s00204012-0980-6

Ankley, G., Bennett, R., Erickson, R. et al. (2010). Adverse outcome pathways: a conceptual framework to support ecotoxicology research and risk assessment. Environ Toxicol Chem 29, 730-741. http://dx.doi.org/10.1002/etc.34

Au, J., Navarro, V. and Rossi, S. (2011). Review article: druginduced liver injury - its pathophysiology and evolving diagnostic tools. Aliment Pharmacol Ther 34, 11-20. http://dx.doi. org/10.1111/j.1365-2036.2011.04674.x

Bauch, C., Kolle, S., Fabian, E. et al. (2011). Intra-laboratory validation of four in vitro assays for the prediction of the skin sensitizing potential of chemicals. Toxicol In Vitro 25, 11621168. http://dx.doi.org/10.1016/j.tiv.2011.05.030

Boobis, A. R., Cohen, S. M., Dellarco, V. et al. (2006). IPCS framework for analyzing the relevance of a cancer mode of action for humans. Crit Rev Toxicol 36, 781-792. http://dx.doi. org/10.1080/10408440600977677

Boobis, A. R., Doe, J. E., Heinrich-Hirsch, B. et al. (2008). IPCS framework for analyzing the relevance of a noncancer mode of action for humans. Crit Rev Toxicol 38, 87-96. http://dx.doi. org/10.1080/10408440701749421

Bradbury, S. P., Feijtel, T. C. and Van Leeuwen, C. J. (2004). Meeting the scientific needs of ecological risk assessment in a regulatory context. Environ Sci Technol 38,463A-470A. http:// dx.doi.org/10.1021/es040675s

Bradford-Hill, A. (1965). The environment and disease: association or causation? Proc $R$ Soc Med 58, 295-300.

Carmichael, N., Bausen, M., Boobis, A. R. et al. (2011). Using mode of action information to improve regulatory decision making: an ECETOC/ILSI/HESI workshop overview. Crit Rev Toxicol 41, 175-186. http://dx.doi.org/10.3109/10408444. 2010.541225

Celander, M. C., Goldstone, J. V., Denslow, N. D. et al. (2011), Species extrapolation for the $21^{\text {st }}$ century. Environ Toxicol Chem 30, 52-63. http://dx.doi.org/10.1002/etc.382

Clewell, H. J., Gentry, P. R., Gearheart, J. M. et al. (1995). Considering pharmacokinetic and mechanistic information in cancer risk assessments for environmental contaminants: examples with vinyl chloride and trichloroethylene. Chemosphere 31, 2561-2578. http://dx.doi.org/10.1016/0045-6535(95)00124-Q

ECETOC - European Centre for Ecotoxicology and Toxicology of Chemicals (2007). Intelligent testing strategies in ecotoxicology: Mode of action approach for specifically acting chemicals. Technical Report 102, Brussels, Belgium.

EC - European Commission (2013a). EURL ECVAM Recom- mendation on the Direct Peptide Reactivity Assay (DPRA) for Skin Sensitisation Testing. Institute for Health and Consumer Protection, Joint Research Centre, Ispra, Italy

EC (2013b). EURL ECVAM Strategy for Replacement of Animal Testing for Skin Sensitisation Hazard Identification and Classification. Institute for Health and Consumer Protection, Joint Research Centre, Ispra, Italy

EC (2014). EURL ECVAM Recommendation on the KeratinoSense $^{\mathrm{TM}}$ for Skin Sensitisation Testing. Institute for Health and Consumer Protection, Joint Research Centre, Ispra, Italy.

Goodman, Z. (2007). Neoplasms of the liver. Mod Pathol 20, S49-S60. http://dx.doi.org/10.1038/modpathol.3800682

Guengerich, F. (2008). Cytochrome p450 and chemical toxicology. Chem Res Toxicol 21, 70-83. http://dx.doi.org/10.1021/ tx700079z

Holt, M. and Ju, C. (2006). Mechanisms of drug-induced liver injury. The AAPS J 8, E48-E54. http://dx.doi.org/10.1208/ aapsj080106

Iorio, F., Bosotti, R., Scacheri, E. et al. (2010). Discovery of drug mode of action and drug repositioning from transcriptional responses. Proc Natl Acad Sci U S A 107, 14621-142626. http:// dx.doi.org/10.1073/pnas.1000138107

Jaworska, J., Harol, A., Kern, P. S. and Gerberick, G. F. (2011). Integrating non-animal test information into an adaptive testing strategy - skin sensitization proof of concept case. ALTEX 28, 211-225. http://dx.doi.org/10.14573/altex.2011.3.211

Kaplowitz, N. (2005). Idiosyncratic drug hepatotoxicity. Nat Rev Drug Disc 4, 489-499. http://dx.doi.org/10.1038/nrd1750

Kleensang, A., Maertens, A., Rosenberg, M. et al. (2014). Pathways of Toxicity. ALTEX31,53-61.http://dx.doi.org/10.14573/ altex.1309261

Kramer, V. J., Etterson, M. A., Hecker, M. et al. (2011). Adverse outcome pathways and ecological risk assessment: Bridging to population-level effects. Environ Toxicol Chem 30, 64-76. http://dx.doi.org/10.1002/etc.375

Lambrechts N, V. H., Witters, H., Van Den Heuvel, R. et al. (2010). Assessment of chemical skin sensitizing potency by an in vitro assay based on human dendritic cells. Toxicol Sci 116, 122-129. http://dx.doi.org/10.1093/toxsci/kfq108

Landesmann, B., Goumenou, M., Munn, S. and Whelan, M. (2012). Description of Protoype Modes-of-action related to repeated dose toxicity. Ispra, Italy: European Commission, Joint Research Centre, JRC Scientific and Policy Report 75689. http://publications.jrc.ec.europa.eu/repository/handle/ $111111111 / 27015$

McKim, J. J., Keller, D. and Gorski, J. (2012). An in vitro method for detecting chemical sensitization using human reconstructed skin models and its applicability to cosmetic, pharmaceutical, and medical device safety testing. Cutan Ocul Toxicol 31, 292305. http://dx.doi.org/10.3109/15569527.2012.667031

Meek, M., Bucher, J., Cohen, S. et al. (2003). A Framework for human relevance analysis of information on carcinogenic modes of action. Crit Rev Toxicol 33, 591-653. http://dx.doi. org/10.1080/713608373

Meek, M. E., Boobis, A., Cote, I. et al. (2014). New developments in the evolution and application of the WHO/IPCS framework on mode of action/species concordance analysis. J Appl Toxi- 
col 34, 1-18. http://dx.doi.org/10.1002/jat.2949

Natsch, A., Ryan, C. A., Foertsch, L. et al. (2013). A dataset on 145 chemicals tested in alternative assays for skin sensitization undergoing prevalidation. J Appl Toxicol 33, 1337-1352.

NRC - National Research Council (2007). Toxicity Testing in the $21^{\text {st }}$ Century: A Vision and a Strategy. Washington, DC, USA: National Academy of Sciences.

Nichols, J. W., Breen, M., Denver, R. J. et al. (2011), Predicting chemical impacts on vertebrate endocrine systems. Environ Toxicol Chem 30, 39-51. http://dx.doi.org/10.1002/etc.376

OECD - Organization for Economic Coordination and Development (2008). Report of the Second Survey on Available Omics Tools. OECD Environment, Health and Safety Publications Series on Testing and Assessment No. 100. ENV/JM/ MONO(2008)35.

OECD (2009). Report of the Expert Consultation to Evaluate an Estrogen Receptor Binding Affinity Model for Hazard Identification. Series on Testing and Assessment, No. 111. Paris: Organization for Economic Co-Operation and Development (OECD), Task Force on Hazard Assessment. http://search. oecd.org/officialdocuments/displaydocumentpdf/?cote=env/ $\mathrm{jm} / \mathrm{mono} \% 282009 \% 2933 \&$ doclanguage $=$ en (accessed 19.09 . 2013).

OECD (2011). Report of the Workshop on Using Mechanistic Information in Forming Chemical Categories. Series on Testing and Assessment, No. 138. Paris: Organization for Economic Co-operation and Development (OECD). http://search. oecd.org/officialdocuments/displaydocumentpdf/?cote=env/ jm/mono\%282011\%298\&doclanguage=en (accessed 19.09 . 2013).

OECD (2012). The Adverse Outcome Pathway for Skin Sensitisation Initiated by Covalent Binding to Proteins, Part 1: Scientific Evidence. Series on Testing and Assessment, No.168. Paris: Organisation for Economic Co-operation and Development (OECD). http://search.oecd.org/officialdocuments/ displaydocumentpdf/?cote=env/jm/mono\%282012\%2910/ part1\&doclanguage $=$ en $($ accessed 19.09.2013).

OECD (2013). Guidance Document on Developing and Assessing Adverse Outcome Pathways. Series on Testing and Assessment, No. 184. Paris: Organization for Economic Cooperation and Development (OECD). http://search.oecd. org/officialdocuments/displaydocumentpdf/?cote $=$ env/jm/ mono\%282013\%296\&doclanguage $=$ en $\quad$ (accessed 21.05 . 2014).

Perkins, E. J., Chipman, J. K., Edwards, S. et al. (2011). Reverse engineering adverse outcome pathways. Environ Toxicol Chem 30, 22-38. http://dx.doi.org/10.1002/etc.374

Parsons, T. (2011). CAAT Receives \$6 Million NIH Director's Grant to Pioneer Transformative Research in Toxicology Testing. Johns Hopkins Bloomburg School of Public Health: http:// www.jhsph.edu/news/news-releases/2011/hartung-nih-award. html (accesssed 19.09.2013).

Rao, M. and Reddy, J. (2004). PPARa in the pathogenesis of fatty liver disease. Hepatology 40, 783-786. http://dx.doi. org/10.1002/hep.20453

Schadt, E. E. and Lum, P. Y. (2006). Reverse engineering gene networks to identify key drivers of complex disease pheno- types. J Lipid Res 47, 2601-2613. http://dx.doi.org/10.1194/jlr. R600026-JLR200

Schmieder, P. K., Tapper, M. A., Denny, J. S. et al. (2004). Use of trout liver slices to enhance mechanistic interpretation of estrogen receptor binding for cost-effective prioritization of chemicals within large inventories. Environ Sci Technol 38, 6333-6342. http://dx.doi.org/10.1021/es0495314

US EPA - US Environmental Protection Agency (2006). Presentation to the $39^{\text {th }}$ Joint Meeting of the Chemicals Committee and the Working Party on Chemicals: Experiences using integrated approaches to fulfill information requirements for Testing and Assessment. http://www.oecd.org/ env/chemicalsafetyandbiosafety/36286164.pdf (accessed 19.09.2013).

US EPA (2007). Framework for Determining a Mutagenic Mode of action for Carcinogenicity: Using EPA's 2005 Cancer Guidelines and Supplemental Guidance for Assessing Susceptibility from Early-Life Exposure to Carcinogens. http://www.epa. gov/osa/mmoaframework/pdfs/MMOA-ERD-FINAL-83007. pdf (accessed 29.12.2013).

US EPA (2012). Prioritization of the Endocrine Disruptor Screening Program Universe of Chemicals for an Estrogen Receptor Adverse Outcome Pathway Using Computational Toxicology Tools. http://www.regulations.gov; docket number EPA-HQOPP-2012-0818 (accessed 15.01.2013).

US FDA - US Food and Drug Administration (2009). Guidance for industry - Drug-induce liver injury: premarketing clinical evaluation. Silver Springs: Office of Communications, Division of Drug Information, Center for Drug Evaluation and Research, FDA. http://www.fda.gov/downloads/Drugs/.../ Guidances/UCM174090.pdf (accessed 19.09.2013).

Villeneuve, D. and Garcia-Reyero, N. (2011). Vision \& strategy: Predictive ecotoxicology in the $21^{\text {st }}$ century. Environ Toxicol Chem 30, 1-8. http://dx.doi.org/10.1002/etc.396

Watanabe, K. H., Andersen, M. E., Basu, N. et al. (2011), Defining and modeling known adverse outcome pathways: Domoic acid and neuronal signaling as a case study. Environ Toxicol Chem 30, 9-21. http://dx.doi.org/10.1002/etc.373

Willett, C., Caverly Rae, J., Goyak, K. O. et al. (2014). Building shared experience to advance practical application of pathwaybased toxicology: Liver toxicity mode-of-action. ALTEX 31, 500-519. http://dx.doi.org/10.14573/altex.1401281

\section{Acknowledgments}

The authors would like to thank Marilyn Matevia for editorial assistance.

\section{Correspondence to}

\section{Catherine Willett, PhD}

The Humane Society of the United States

700 Professional Drive

Gaithersburg, MD 20879, USA

e-mail: KWillett@humanesociety.org 